\title{
MÉMORIAS DE EXPERIÊNCIAS NO ESTÁGIO SUPERVISIONADO: INDISCIPLINA EM SALA DE AULA E O USO DE GÊNEROS TEXTUAIS ${ }^{1}$
}

\author{
Joaline Soares Damasceno de Melo, UFCG, \\ joalinemelo@gmail.com
}

\begin{abstract}
RESUMO
O presente artigo é fruto da experiência vivenciada na etapa prática da disciplina Estágio supervisionado nos anos iniciais do ensino fundamental do Centro de Formação de Professores, da Universidade Federal de Campina Grande - Campus de Cajazeiras/PB. O mesmo tem por objetivo relatar a aplicabilidade dos gêneros textuais como instrumento reflexivo acerca da indisciplina em sala de aula. De forma específica memoriar alguns gêneros utilizados e dialogar a interação dos textos com os conflitos disciplinares dos alunos em sala de aula. A metodologia de abordagem qualitativa deu-se através da pesquisa de campo e em ação com uma turma do $5^{\circ}$ Ano de uma Escola Municipal da periferia da cidade de Cajazeiras, alto sertão paraibano. O primeiro momento de observação na escola forneceu um diagnóstico e com base nele, em consonância com o professor regente da sala foram preparadas as aulas. Trabalhar a literatura de cordel e outros gêneros textuais aplicando-os à realidade na qual a escola está inserida mostrou-se perfeitamente capaz para dialogar sobre a indisciplina em sala de aula.
\end{abstract}

PALAVRAS-CHAVE: Estágio Supervisionado; Indisciplina; Gêneros textuais.

\section{INTRODUÇÃO}

O estágio representa um período indispensável na vida do acadêmico do curso de Licenciatura plena em Pedagogia, como preparação para o ingresso no cenário profissional, como dialogo das teorias estudadas e suas aplicabilidades.

O propósito em questão é investigar as relações que se colocam no cotidiano escolar e construir saberes mediante reflexão socialmente contextualizada e teoricamente fundamentada sobre a prática docente: "saber observar, descrever, registrar, interpretar e problematizar e, consequentemente, propor alternativas de intervenção" (PIMENTA, 2001, p. 76) e de superação.

Já era esperado de antemão que haveria dificuldades em questões de disciplina pelo contexto no qual a escola onde seria realizado o estágio está inserida, bem como pelo ano da

\footnotetext{
${ }^{1} \mathrm{O}$ presente trabalho (não) contou com apoio financeiro de nenhuma natureza para sua realização.
} 
série de ensino que contempla alunos que estão vivenciando a transição da fase infantil para a adolescência.

Mediante essa realidade foi pensado a partir da $1^{\text {a }}$ fase que é de observação e preparado para a $2^{\mathrm{a}}$ fase de intervenção uma abordagem de ensino que promovesse não apenas a aprendizagem de conteúdos, mas também reflexão nas atitudes, por isso a utilização dos gêneros textuais.

\section{A QUESTÃO DA (IN) DISCIPLINA DOS ALUNOS}

É importante considerar que existe uma série de fatores que contribuem com a questão da indisciplina, além do próprio contexto escolar, como: formação da família, o aumento das drogas, violência na comunidade, desinteresse por parte do educando, ausência da sociedade, falta do diálogo, entre outros. Todos esses fatores afetam direta ou indiretamente as relações existentes no contexto escolar: "professor x aluno" "aluno x aluno".

Sendo reconhecido com um problema que envolve a todos, é o professor que lida de forma mais direta e constante com essa problemática, afetando diretamente os processos de ensino e de aprendizagem. Entretanto, a responsabilidade sobre a (in) disciplina não pode ser restringido apenas ao professor na sala de aula. Este por sua vez não pode transferir a parte que lhe cabe a outros departamentos, Vasconcellos (1997) afirma existir um equívoco entre os docentes que ele denominou de "Síndrome de Encaminhamento". Uma postura que, segundo o autor, muitos educadores assumem ao se depararem com os conflitos existentes, alimentando a ideia de que a direção ou a coordenação devam ser mais severas na aplicação da disciplina. Continua o seu pensamento, afirmando ser necessário que os conflitos gerados em sala de aula sejam superados pelos agentes envolvidos nesse processo, sendo o professor a tal pessoa mais 'capacitada'. Mas que ele possa contar com os demais da equipe como apoio ( coordenador, direção, psicopedagogo,etc) para lidar da melhor maneira possível, superando assim a "síndrome de encaminhamento".

Sendo o professor o responsável direto para mediar os conflitos em sala de aula, uma possibilidade na qual ele pode provocar um diálogo com os alunos acerca de diversas atitudes em sala de aula e suas consequências, que podem (ou não) acarretar conflitos disciplinares, é a utilização dos gêneros textuais como ferramenta de reflexão e aprendizagem sobre essas ações. 


\title{
GÊNEROS TEXTUAIS - POSSIBILIDADES DE ENSINO
}

A proposta de trabalhar com os gêneros textuais na disciplina de língua portuguesa está prevista nos Parâmetros Curriculares Nacionais (PCN's) como forma de expandir o uso da linguagem , considerando as possibilidades linguísticas básicas

[...] Quando se afirma, portanto, que a finalidade do ensino de Língua Portuguesa é a expansão das possibilidades do uso da linguagem, assume-se que as capacidades a serem desenvolvidas estão relacionadas às quatro habilidades linguísticas básicas: falar, escutar, ler e escrever. (PCN, 1997, p.35).

Seria essa a ideia principal fazer com que os alunos desenvolvam a linguagem aprendendo através da diversidade de textos que provoque reflexões na escuta, mas também promovendo o conhecimento no desenvolver da leitura e escrita. Daí os gêneros textuais, como bem define Marcuschi (2005), dão conta de toda essa abrangência sócio-comunicativa

\begin{abstract}
Usamos a expressão gênero textual como uma noção propositalmente vaga para referir os textos materializados que encontramos em nossa vida diária e que apresentam características socio-comunicativas definidas por conteúdos, propriedades funcionais, estilo e composição característica. Se os tipos textuais são apenas meia dúzia, os gêneros são inúmeros. Alguns exemplos de gêneros textuais seriam: telefonema, sermão, carta comercial, carta pessoal, romances, bilhete, reportagem jornalística, aula expositiva, reunião de condomínio, noticia jornalística, [...] piada, conversação espontânea, conferencia, carta eletrônica, bate-papo por computador, aulas virtuais e assim por diante. (MARCUSCHI,2005, p. 22-23)
\end{abstract}

Além de que, os gêneros textuais, afirma Bazerman (2005) "emergem nos processos sociais em que pessoas tentam compreender umas às outras suficientemente bem para coordenar atividades e compartilhar significados com vistas a seus propósitos práticos" (BAZERMAN, 2005, p. 31).

Portanto, mais do que ensinar um gênero o professor compreende a importância 'do quê ensinar' por meio dele. 


\section{METODOLOGIA}

Do ponto de vista metodológico, o trabalho realizou-se segundo uma abordagem qualitativa e quanto ao procedimento vale-se das contribuições da pesquisa de campo e em ação durante o estágio supervisionado do curso de Pedagogia, que ocorreu no ano de 2016, sob a disciplina: Estágio Supervisionado nos Anos Iniciais do Ensino Fundamental do Centro de Formação de Professores, da Universidade Federal de Campina Grande - Campus de Cajazeiras/PB. O estágio foi feito com uma turma do $5^{\circ}$ ano de uma Escola Municipal na periferia da cidade de Cajazeiras no Estado da Paraíba e contou com a participação cooperativa de outro sujeito. O estágio teve dois momentos: A primeira semana de observação na sala e segunda semana, a fase da intervenção.

\section{O PRIMEIRO MOMENTO: A OBSERVAÇÃO}

A atividade docente é caracterizada por uma grande complexidade do ponto de vista emocional, pois o professor vive em um espaço carregado de afetos, sentimentos e de conflitos, e por vezes prefere não se envolver. Mas tal atitude seria a negação da própria constituinte do ser professor. (Nóvoa, 2002. p.24) Uma das dificuldades observadas na primeira semana, o mau comportamento que três alunos apresentavam e tentavam chamar a atenção dos demais na sala de aula. A professora convivia com essa situação dia após dia. Observamos que a docente sempre procurava conversar com os alunos e em última instância encaminhar para a gestão.

Nos dias da observação ocorreu uma das situações de indisciplina por parte dos alunos da sala a qual observávamos, mas a professora valeu-se nesse momento de seu direito de encaminhar o conflito para a gestão, pois o fato ocorrido se dera no horário do recreio, e, segundo a docente cabe à direção resolver, muito embora fossem seus alunos. A vice-diretora por sua vez, já ciente do ocorrido, e mesmo tendo tido um breve encontro na direção com os envolvidos, preferiu ir à sala de aula e diante de toda turma repreender novamente os envolvidos na agressão. Alertou-os que tal atitude não seria tolerada novamente e os pais seriam chamados, se necessário para sanções punitivas. Segundo Vasconcellos (1997) é importante, construir uma linha comum de atuação em que todos possam contribuir: falando a 
'mesma linguagem'; não deixar que se tenha apenas "um” que cuide da disciplina, não se pode perder a visão de conjunto.

Também houve outro conflito procedente do lado externo da escola, mas objetivando a sala de aula que estávamos - o 5 ano. Em dado momento da aula uma pedra é arremessada de fora atravessando a janela e quase atingindo um dos alunos. Todos ficaram assustados, mas a professora disse que já houve situação semelhante em anos anteriores. O fato repetiu-se na quarta feira, mas desta vez um dos alunos conseguiu ver a procedência, era um jovem que havia sido expulso dessa escola por indisciplina. O caso foi notificado e as providências tomadas.

Portanto, essa primeira vivência de observação para o estágio possibilitou um importante conhecimento teórico-prático para dialogarmos e refletirmos tais problemas da instituição e fazermos referência com as teorias estudadas para subsidiar o momento de preparação para a semana de intervenção. A professora repassou a seleção de conteúdos para que o planejamento seguisse de acordo com o programa curricular proposto pela escola.

\section{O SEGUNDO MOMENTO: A INTERVENÇÃO}

No programa de formação docente sugerido por Nóvoa (2002, p.22), ele defende que "É no trabalho individual e coletivo de reflexão que eles encontrarão os meios necessários ao seu desenvolvimento profissional.", compreendemos quão importante foi para o nosso crescimento a semana de intervenção, com todas as expectativas e angustias pertinentes ao processo. Vale ressaltar que fomos bem acolhidos pelos funcionários da escola e tivemos total apoio da professora regente, que nos observava de forma direta e por vezes ausentava-se, mas sempre próxima do ambiente da sala, caso precisássemos, como de fato alguns momentos precisamos.

Não foi muito difícil fazer amizade com as crianças e conquistá-las. Buscou-se dar continuidade ao que a professora passava para as crianças: atenção, carinho e voz. As crianças podiam dar opinião sobre o que foi bom, o que mais gostaram e o que poderia melhorar na aula. Manteve-se assim aberto o diálogo. Durante os 8 dias de intervenção não houve problema que não pudesse ser solucionado: brigas e xingamentos entre os discentes sempre acabavam com um pedido de desculpas, isso mediado por nós ou pela professora regente, e

Revista de Pesquisa Interdisciplinar, Cajazeiras, n. 2, suplementar, p.459-470, set. de 2017. 
em ultima instância, encaminhar para direção. A ideia principal era procurar fazer com que as crianças refletissem sobre as suas ações, e que estas geram consequências para si e para outros. Daí a importância dos gêneros textuais utilizados em sala de aula.

\section{A UTILIZAÇÃO DOS GÊNEROS TEXTUAIS}

As aulas geralmente começavam com a disciplina de língua portuguesa, e houve a possibilidade de trabalhar com a literatura de cordel, sendo esse um dos tópicos previsto no conteúdo programático compartilhado pela professora regente. Foi exposto um painel utilizando-se de um barbante, afinal essa é a ideia primária do próprio nome "cordel", pois na história dessa literatura eram expostos os folhetins dessa forma pendurados em cordas. Assim foi feito também para que chamasse a atenção da turma com as letras do nome C-O-R-D-E-L. Em cada letra uma estrofe de um poema em cordel a ser lida, como um 'acróstico'2

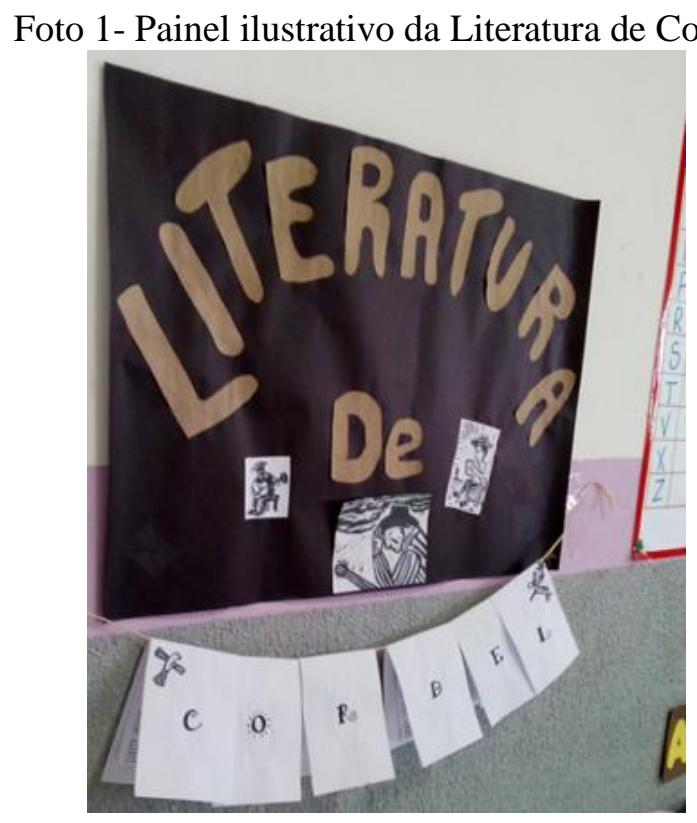

Foto: Joaline S. D. Melo

${ }^{2}$ Acróstico é uma composição poética onde as letras iniciais, intermediárias ou finais formam palavras ou até mesmo frases. Disponível em: http://mundoeducacao.bol.uol.com.br/redacao/acrostico.htm Acesso em: 15/08/17 às 17:10 
Percebeu-se que, embora a literatura de cordel seja da cultura nordestina, existe ainda um desconhecimento, uma estranheza acerca da mesma. Contudo, se percebeu o interesse com o gênero que mais se parece uma arte, e que tem suas raízes tão próximas ao nosso chão. Conforme Pontes (2013)

\begin{abstract}
A arte, trata-se da melhor forma de chamar à atenção do aluno, pois propicia o desenvolvimento do pensamento artístico, que se caracteriza em um eu particular de cada aluno. A questão do ensino da leitura literária, envolve um exercício de reconhecimento, fazendo estarem presentes na escola em relação aos textos literários. Daí surge a Literatura de Cordel, como meio incentivador para o ensino de literatura. Na verdade, essa Literatura bastante desconhecida aqui mesmo na região nordestina, onde dela se extrai um grande número de cordelistas, percebe-se que as escolas não trabalham esse tipo de literatura, que é bastante excluída nas salas de aula, bem como nos livros didáticos. (PONTES, 2013, on line)
\end{abstract}

A temática disposta no acróstico era sobre um menino que não sabia ler, pois trabalhava na roça, até que conseguiu mais tarde quando já era quase um adulto. Aproveitouse para trazer a discussão provocando a reflexão, pois também sabíamos que a realidade daquele menino não era estranha a de muitos alunos. E assim, deixar o incentivo para que estudem enquanto ainda estão na infância. Foi dada a oportunidade para quem quisesse vir e ler cada uma das estrofes. Naquele dia havia chegado uma aluna novata e ela se prontificou a ler. Qual a surpresa de todos ao ver que a aluna tinha certa dificuldade na fala, mas que não comprometia sua aptidão cognitiva. Isso ficou claro no decorrer dos dias. Não obstante, afora alguns risinhos contidos, todos ouviram com atenção e a turma comportou-se bem diante da situação. Agradecemos sua participação e incentivamos outros a ler novamente a mesma estrofe para que se tornasse mais clara sem, entretanto dizermos que a aluna leu ininteligível.

E para ajudar a trazer esse conhecimento histórico da literatura de cordel, passamos um curto documentário falando do primeiro folheto que se teve noticia e que foi publicado na Paraíba por Leandro Gomes de Barros, em 1893. Foi interessante ver o semblante de interesse e surpresa nos rostos dos alunos. O documentário também mostrou uma música que o famoso Luiz Gonzaga interpretou a partir de um poema em Cordel de Patativa do Assaré. A partir disso a aula também dialogou com a disciplina de geografia, porque Assaré é uma cidade do estado do Ceará não muito distante de Cajazeiras.

Foi possível trabalhar ao longo da semana outras temáticas pertinentes às realidades vividas pela comunidade escolar, tendo como foco algumas que se destacavam ações

Revista de Pesquisa Interdisciplinar, Cajazeiras, n. 2, suplementar, p.459-470, set. de 2017. 
geradoras da indisciplina, de forma especial quando trabalhamos acerca do Bulling, foi possível identificar no cordel: "Bulling, isso não tem graça nenhuma", atitudes que os alunos tinham e que por agirem daquela forma as brigas aconteciam. A ideia era essa, fazer com que eles refletissem na leitura as próprias ações e consequências. Outros temas chamaram a atenção: "Se droga fosse bacana, não tinha o nome que tem"; Nesse cordel era possível ouvir de alguns acusações de quem estava metido com drogas. Esse era o momento também de alertá-los para os perigos, uma vez que já tínhamos conhecimento da realidade de vulnerabilidade social do bairro. Por fim trabalhamos o "Cordel da Zica, Dengue e Chicungunha", inclusive na semana seguinte haveria uma ação da prefeitura sobre a prevenção do mosquito.

Além destes, temas envolvendo a gramática: "Cordel dos Substantivos" bem como outros gêneros textuais semelhantes como adivinhas e poemas.

Uma produção textual foi solicitada a partir do gênero filme apresentado na sala de vídeo, o filme biográfico contando a história do Dr Ben Carson, envolvendo questões como pobreza, racismo, violência e a superação de todos esses fatores. Houve ainda a contação de história sobre a vida de Martin Luther King, com destaque para o seu último discurso: "Eu tenho um sonho". Esse foi o tema para que produzissem um texto. Sendo assim, já na discussão sobre o tema, foi possível ouvi-los contar de seus sonhos ou mesmo pesadelos. Inclusive percebemos nas narrativas a preocupação de alguns com respeito a temas já abordados nas literaturas de cordel acerca do preconceito. Através da correção de algumas dessas produções pudemos trabalhar a gramática ao observar quais os erros predominantes. Erros comuns como iniciar a frase com letra minúscula. A professora regente ficou com as produções para que pudesse intervir melhor posteriormente nos erros apresentados.

Para além das possibilidades do ensino de conteúdos gramaticais, o que se destaca é o despertar da consciência, é provocar uma reflexão através da diversidade dos gêneros textuais, histórias escritas em versos ou prosa, cantadas ou contadas através de músicas, documentários e filmes, são conflitos vivenciados e superados pelos autores, mas que muitas vezes retratam experiências na qual os alunos estão vivendo. Daí a importância do diálogo no qual é possível fazer a interação com a vida escolar e aplicar princípios que tragam reflexões para os alunos sobre as atitudes de indisciplina em sala de aula, e até mesmo fora dela. 
Ao descrever essas memórias recorda-se da existência de uma construção acontecendo, mesmo em meio às crises, aliás, elas são necessárias para o crescimento. Pimenta fala sobre a seguinte colaboração que nos serve de reflexão para nossa formação:

\begin{abstract}
Através do exercício da profissão o graduando terá oportunidade de trabalhar os conteúdos e as atividades do estágio no campo de seu conhecimento específico, que é a Pedagogia-ciência da educação- e a Didática-que estuda o ensino e a aprendizagem-, percebem que os problemas e possibilidades de seu cotidiano serão debatidos, estudados e analisados à luz de uma fundamentação teórica e, assim, fica aberta a possibilidade de se sentirem co-autores desse trabalho. O estágio passa a ser um retrato vivo da prática docente e professor-aluno terá muito a dizer, a ensinar, a expressar sua realidade e de seus colegas de profissões, de seus alunos, que nesse mesmo tempo histórico vivenciam os mesmos desafios e as mesmas crises na escola e na sociedade. Nesse processo, encontram possibilidade para ressignificar suas identidades profissionais, pois estas, como vimos, não são algo acabado. (PIMENTA 2004, p.127).
\end{abstract}

Isso, portanto se dá na sociedade, na escola, nos alunos, em nossa identidade profissional. A realidade vivenciada no estágio proporcionou inúmeras experiências que serão readaptadas através de novas vivências ao longo da carreira profissional.

\title{
CONSIDERAÇÕES FINAIS
}

Ao relatar a aplicabilidade dos gêneros textuais, como instrumento reflexivo acerca da indisciplina em sala de aula foi possível através da literatura de cordel, documentário, filme, entre outros, proporcionando o diálogo sobre atitudes causadoras de indisciplina nos alunos provocando reflexões mútuas nos atores em sala de aula ( professor $\mathrm{x}$ aluno $\mathrm{x}$ aluno) mas também de forma indireta envolvendo os demais que fazem parte da escola e também lidam com as questões disciplinares. Os gêneros textuais utilizados favoreceram ao debate em sala visando à superação de um saber fragmentado aplicando-os à realidade dos alunos na comunidade a qual a escola está inserida.

A escola, de fato não se restringe apenas a sala de aula, por isso agradeço o apoio que tivemos da professora regente e demais atores. Também sou grata a Deus que me deu a oportunidade de fazer parte dessa comunidade onde a escola está localizada, e por isso já ter uma maior abertura com alguns alunos, inclusive aqueles de maior dificuldade com relação à indisciplina. Conhecê-los um pouco mais. Fazer-se e fazê-los compreender-se mais. 
Reconheço a importância que o estágio teve para o meu desenvolvimento pessoal e profissional. Os desafios foram muitos. Ouvimos de colegas que desistiram do estágio porque não soube lidar com a indisciplina dos alunos. Houve momentos difíceis, mas creio que, justamente esses momentos é que nos proporcionou um crescimento maior. Os temas de indisciplina e o uso dos gêneros textuais como proposto neste trabalho são complexos e desafiadores também. Trazê-los à memória e deixar registrado neste trabalho é um começo, mas também se torna didático e motivador para que outros estudos sejam feitos e aprofundados.

\title{
EXPERIENCES OF EXPERIENCES IN THE SUPERVISED STAGE: INDISCIPLINA IN A CLASSROOM AND THE USE OF TEXTUAL GENRES
}

\begin{abstract}
This paper aims to report the applicability of textual genres as a reflection about the indiscipline in the classroom. Thus, to memorize some used genres and to dialogue the interaction of the texts with the disciplinary conflicts of the students in the classroom. The methodology of qualitative approach with field research and in action in a class of the 5th year. Working the textual genres applying them to the school reality was able to dialogue about the indiscipline in the classroom.
\end{abstract}

KEYWORDS: Supervised internship; Indiscipline; Textual genres

\section{MÉMORIAS DE EXPERIENCIAS EN LA ETAPA SUPERVISADA: INDISCIPLINA EN SALA DE CLASE Y EL USO DE GÉNEROS TEXTUALES}

\begin{abstract}
RESUMEN
Este trabajo objetiva relatar la aplicabilidad de los géneros textuales como reflexión acerca de la indisciplina en el aula. Así, memorizar algunos géneros utilizados y dialogar la interacción de los textos con los conflictos disciplinares de los alumnos en el aula. La


metodología de abordaje cualitativo con investigación de campo y en acción en una clase del $5^{\circ}$ año. Trabajar los géneros textuales aplicándolos a la realidad escolar se mostró capaz de dialogar sobre la indisciplina en el aula.

PALABRAS CLAVES: Etapa Supervisada; Indisciplina; Géneros textuales

\section{REFERÊNCIAS BIBLIOGRÁFICAS}

BAZERMAN, C. (2005). Gêneros textuais, tipificação e Interação. (orgs. Angela Paiva Dionisio \& Judith Chambliss Hoffnagel) São Paulo: Cortez.

BRASIL, Secretaria de Educação Fundamental. Parâmetros curriculares nacionais: Língua Portuguesa / Secretaria de Educação Fundamental. Brasília: MEC/SEE, 1997.

COSCARELLI, Carla Viana. Gêneros textuais na escola. (FALE/ UFMG).Disponível em: < http://www.ufjf.br/revistaveredas/files/2009/12/artigo051.pdf > Acesso em 07/08/17

MARCUSCHI, Luis Antônio. Gêneros textuais: definição e funcionalidade. In: DIONÍSIO, A. P.; MACHADO, A. R.; BEZERRA, M. A. (Orgs.). Gêneros textuais e ensino. 2. ed. Rio de Janeiro: Editora Lucerna, 2005.

NÓVOA, A. Formação de professores e trabalho pedagógico. Lisboa: Educa, 2002.

PIMENTA, Selma Garrido. O estágio na formação de professores: unidade teoria e prática? 4.ed. - São Paulo: Cortez, 2001.

- Estágio e docência ( Coleção decência em Formação. Séries Saberes

Pedagógicos), 2. ed. - São Paulo: Cortez,2004.

PONTES, Marcos Antonio. A Literatura de Cordel Como Fonte de Incentivo no Ensino de Literatura. Pedagogia ao Pé da Letra, 2013. Disponível em: . Acesso em: 03 de agosto de 2017 
VASCONCELLOS, Celso dos Santos. Os Desafios

de Aula e na Escola. Série Idéias, São Paulo, n. 28, p. 227-252, 1997 